\title{
Hydrocarbon-induced clay and carbonate minerals interpretation in Songliao Basin using ASTER data
}

\author{
Guifang Zhang, Zhenqiang Shao, Yuanhua Huang
}

\begin{abstract}
Advanced Spaceborne Thermal Emission and Reflection Radiometer (ASTER) data were used to interpret hydrocarbon-induced clay and carbonate minerals in northwestern Songliao Basin, northeast China. Principal component analysis (PCA), band ratioing, and density slicing were adopted to distinguish the goal area of clay and carbonate minerals. Four principal components showed outstanding spectral response of hydrocarboninduced clay and carbonate minerals: 5689-PC2 (the second principal component of input bands 5689), 1589-PC3, 1689-PC3 and 1348-PC. Then, density slicing was used to highlight the pixels with the largest DN (digital number) of PC images as the area of clay and carbonate minerals. The result suggests that hydrocarbon microseepage-induced mineral assemblage is related closely to the surface sediments. Compared with the anomalous area of ETM+ data, the distinguished area from ASTER datahas almost the same distribution, but more widely.
\end{abstract}

Keywords: Hydrocarbon-induced $\bullet$ clay and carbonate minerals $\cdot$ ASTER $\cdot$ Songliao Basin

\section{Introduction}

Oil and gas seepage from underground reservoirs has been noted for thousands of years. The escape of hydrocarbons causes a number of alterations (e.g. anomalous hydrocarbon concentrations, clay and carbonate minerals formations, magnetic iron oxide and sulfide assemblages, and microbial effects) in rocks, soils, and vegetative cover that overlie oil and gas reservoirs. As a result, microbial and botanical anomalies, mineralogic changes, and alterations of electrical, magnetic, and seismic properties occur in near-surface sediments (Donovan, 1974; Matthews, 1986; Segal and Merin, 1989; Schumacher, 1996).

In last three decades, the rapid development of remote sensing technology has evolved dramatically to include a suite of sensors of diversified resolutions with potential interest and importance to geologists and petroleum engineers. Remote sensing offers various advantages including the provision of spatial, spectral, and temporal data covering large andinaccessible areas within a short time; it is thus a handy tool for identifying natural resources in a cost- and labour-effective manner. The identification of an area with hydrocarbon microseepage using remote sensing is a search for surface occurrences of hydrocarbons and their alteration products, which serve as clues to the location of undiscovered oil and

G. F. ZHANG (ه)

1. Department of Earth Sciences, Sun Yat-sen University, Guangzhou 510275, China.

2. Guangdong Provincial Key Laboratory of Mineral Resources \& Geological Processes.

E-mail: joyinsummer@163.com

Z. Q. SHAO

China Soutern Power Grid Media Corporation Limited, Guangzhou 510600, China.

Y. H. HUANG

Department of Earth Sciences, Sun Yat-sen University, Guangzhou 510275, China 
gas accumulations. Among these surface/near-surface hydrocarbon microseepage-induced anomalies, the alteration of clay minerals and carbonates exhibit spectral features that can favour their detection by remote sensing techniques (Hunt and Ashley, 1979; Sabins, 1999; Almeida-Filho et al., 2002; Meer et al., 2002).

Advanced Spaceborne Thermal Emission and Reflection Radiometer (ASTER) is a multispectral imaging sensor having 14 bands: three visible and near infrared radiation (VNIR) bands ranging between 0.52 and $0.86 \mu \mathrm{m}$ with a spatial resolution of $15 \mathrm{~m}$; six shortwave infrared radiation (SWIR) bands from 1.6 to $2.43 \mu \mathrm{m}$ with a spatial resolution of $30 \mathrm{~m}$; and five recording thermal infrared radiation (TIR) bands in the 8.125-11.65 $\mu \mathrm{m}$ wavelength region with spatial resolution of $90 \mathrm{~m}$. The six spectral bands of ASTER SWIR subsystem were designed to measure reflected solar radiation to distinguish $\mathrm{Al}-\mathrm{OH}, \mathrm{Fe}, \mathrm{Mg}-\mathrm{OH}, \mathrm{Si}-$ $\mathrm{O}-\mathrm{H}$ and $\mathrm{CO}_{3}$ absorption features (Abrams and Hook, 1995 and Fujisada, 1995). It can provide sufficient capability for the remote identification of clay and carbonate minerals

(Ninomiya, 2003; Rowan et al., 2006) . Moreover, the ASTER VNIR and TIR data is useful for the remote identification of vegetation and iron oxide minerals (Clark, 1999; Bedell, 2001) and carbonates and silicates (Ninomiya, 2003; Rowan et al., 2006).

In this study, ASTER data were used to interpret hydrocarbon microseepage-induced anomalies of clay and carbonate minerals in the northwest part of Songliao Basin, NE China. Spectral enhancements used for the remote sensing images included principal component analysis (PCA) and band ratioing. Then, the anomalous area of clay and carbonate minerals was interpreted from the enhanced images. Finally, the delineated anomalous areas were compared to the hydrocarbon-induced area derived from ETM + data for result validation.

\section{Study area}

The study area is located in the northwest part of Songliao Basin, NE China (Fig. 1(a)). The Songliao Basin is the most important basin for China's petroleum industry and the study area lies within a first-order tectonic unit named the western slope (see Fig. 1 (b)); the regional strike of the strata in this area is NNE. The western slope is a large and nearly flat monocline that dips eastward at angle of less than $1^{\circ}$ and exhibits lithologic contacts in parallel conformity with undeveloped fractures.

\section{ASTER data and process}

\subsection{ASTER data}

One cloud-free level 1B ASTER scene acquired on 22th September 2002 was used. In this time, the vegetative cover is decreased but the ground has not yet frozen, making the ground condition of the study area desirable for satellite data acquisition. ASTER image was processed using the ENVI (Environment for Visualizing Images) version 4.3 software package. 

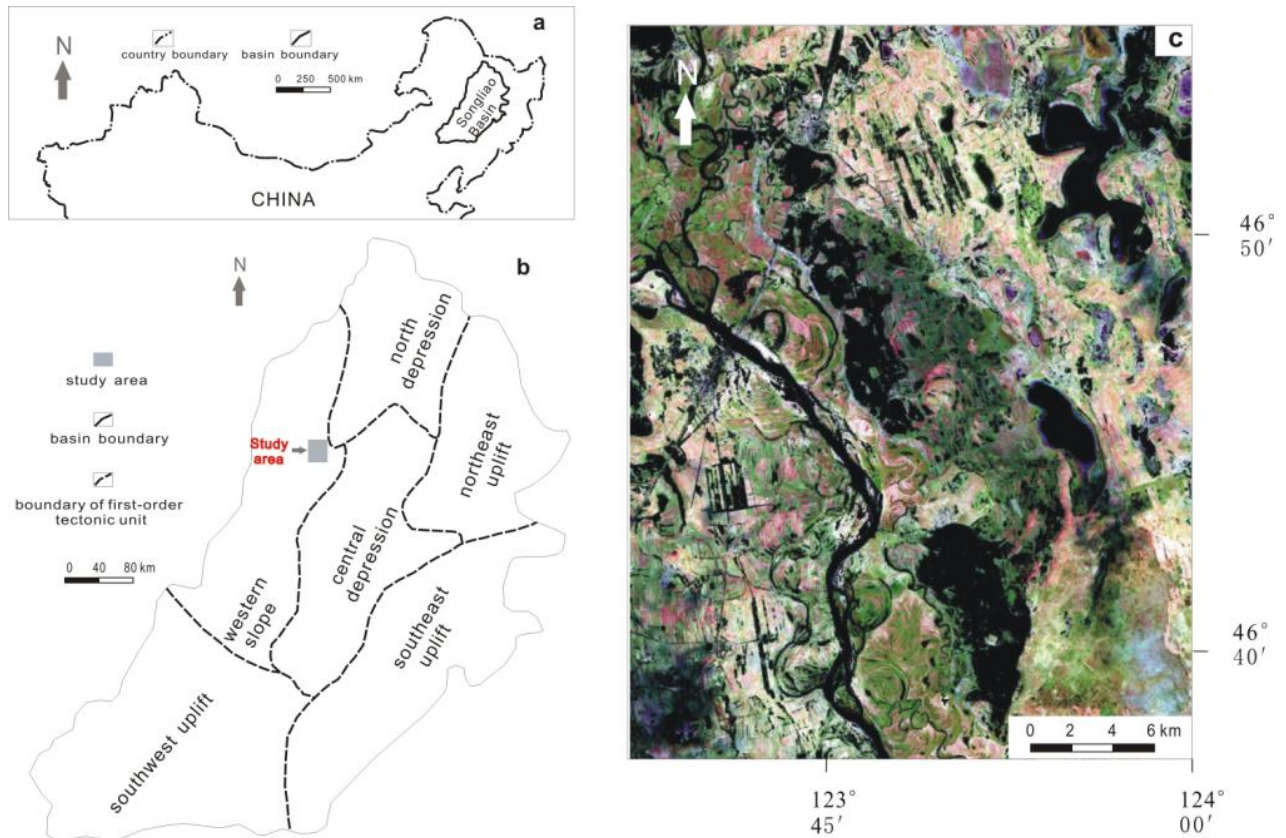

Fig. 1 (a) Location of Songliao Basin in China. (b) Tectonic units of Songliao Basin and study area.

(c) ASTER image of study area.

\subsection{Data preparation}

Before the image process, the storage formation of ASTER data was transformed from BSQ (band sequential) to BIL (band interleaved by line). Then, the atmospheric correction and feature mask of water and vegetation were applied: Atmospheric correction was performed by using the Fast Line-of-sight Atmospheric Analysis of Spectral Hypercubes (FLAASH) algorithm on the data; water mask was performed by Modified Normalized Difference Water Index (MNDWI: (Green-MIR) / (Green+ MIR)) expressed as (band 1band 4) / (band 1+ band 4); vegetation mask was performed by using ratio band 4 / band 3 .

Transverse Mercator projection and Krasovsky spheroid are employed for image geometric correction and the ground control points are picked from the relief maps with the scale of 1:50,000. The resample method is nearest neighbor and the Root Mean Square (RMS) error is 1 pixel. The study area is subset from the resampled image and the study area is $26 \times 34 \mathrm{~km}$ with the upper left coordinate of $\mathrm{X}=548,000, \mathrm{Y}=5,196,000$ and the lower right coordinate of $\mathrm{X}=574,000, \mathrm{Y}=5,162,000$ (Fig. 1(c)).

\subsection{Data process}

The Principal component analysis (PCA), Band ratioing and false color composite are tested to enhance the spectral characteristics of hydrocarbon-induced clay and carbonate minerals. Moreover, density slice was used to demonstrate the anomalous area of the enhanced images. 
1. The Principal component analysis (PCA) makes a linear transformation on an Ndimensional (band) image, creating $\mathrm{N}$ new uncorrelated components known as principal components (PCs), which are aligned with the axis of greatest spectral variability. The Crosta technique based on the examination of PCA eigenvector loadings to decide which of the principal component images will concentrate information directly related to the theoretical spectral signatures of specific targets (Tangestani and Moore, 2002). The Crosta technique can indicate whether the surficial material is highlighted by bright or dark pixels in the principal components according to the magnitude and sign of the eigenvectors (Loughlin, 1991; Ruiz-Armenta and Prol-Lendesma, 1998; Tangestani and Moore, 2002). In analyzing the available spectral bands, this study focused on information unique to bands that indicate the occurrence of hydrocarbon-induced anomalies of clay and carbonate minerals as compared to information that is common to all bands involved. Thus, the selective analysis of Crosta technique is adopted.

2. Band ratio images can be effective in utilizing the full potential of the spectral information and in emphasizing certain features. Thus it has often been adopted for spectral enhancement (Abrams et al., 1983; Sabins, 1997; Tangestani and Moore, 2000; AlmeidaFilho et al., 2002; Meer et al., 2002; Kariuki et al., 2004).

3 . The technique of density slicing was used to highlight the assemblage of clay and carbonate minerals. Density slicing turns a narrow range of pixel values into another color, again with interactive control. By dragging the slice through the range one can obtain a precise way of exploring the values in the image.

\section{Result and discussion}

Clay minerals and carbonates exhibit diagnostic spectral features centred at $1.4 \mu \mathrm{m}, 1.75 \mu \mathrm{m}$, $1.9 \mu \mathrm{m}, 2.20 \mu \mathrm{m}$ and $2.35 \mu \mathrm{m}$ respectively (Hunt and Ashley, 1979). The spectral feature of clay minerals and carbonates on ASTER bands is showed in Table 1.

Table 1 Spectral characteristics of clay and carbonate minerals

\begin{tabular}{lcccccc}
\hline & Band 4 & Band 5 & Band 6 & Band 7 & Band 8 & Band 9 \\
\hline Band range $(\mu \mathrm{m})$ & $1.60-1.70$ & $2.145-2.185$ & $2.185-2.225$ & $2.235-2.285$ & $2.295-2.3652 .360-2.430$ \\
Spectral characteristic & Reflect & Reflect & Reflect & Absorb & Absorb & Reflect \\
\hline
\end{tabular}

Four ASTER bands were selected from ASTER VNIR and SWIR bands (band 1-9) for PCA composition. According to spectral characteristics of clay and carbonate minerals and in accordance with the eigenvectors of every PCA, 5689-PC2 (the second principal component of input bands 5689), 1589-PC3, 1689-PC3 and 1348-PC3 were found to have relatively good enhancement (shown in Table 2 and Fig. 2).

It is evident that clay and carbonate minerals manifest as light pixels in 5689-PC2 because of positive contribution from band $5(0.464)$ and $6(0.349)$, and negative contribution from band $8(-0.811)$. Due to negative contributions from band $8(-0.727)$ and positive from band $5(0.670)$ and band $9(0.091)$ for $1589-\mathrm{PC} 3$, it is indicated that clay and carbonate minerals would be distinguished as bright pixels, and so is 1689-PC3. Because of negative weighting of band $4(-0.626)$ and positive weighting of band 8 (0.746), 1348-PC3 distinguishes clay and carbonate minerals as bright pixels from the background.

Refer to the spectral feature of clay and carbonate minerals on ASTER bands showed in Table 1, many band ratios were tested for enhancement, such as 5/7, 5/8, $(5+6) /(7+8), 6 / 7$, 
$6 / 8,6 /(7+8)$, and so on. However, result showed the band ratio images are not good enough for clay and carbonate minerals recognition in study area.

Then, density slicing was used to highlight the pixels with the largest DN (digital number) of every PC image based on the threshold of $X+2 \sigma \quad(X$ is the average value and $\sigma$ is the standard deviation). The selected pixels of four PC images were showed in different colors respectively (Fig. 3(b)) and the identified area of hydrocarbon-induced clay and carbonate minerals from the four PC images was listed in Table 2.

Table 2 Principal components analysis on VNIR and SWIR bands of ASTER

\begin{tabular}{ccccc}
\hline & PC1 & PC2 & PC3 & PC4 \\
\hline Input bands (5689) & & & & \\
\hline band 5 & 0.523 & 0.464 & 0.255 & -0.667 \\
band 6 & 0.541 & 0.349 & -0.635 & 0.425 \\
band 8 & 0.497 & -0.811 & -0.185 & -0.244 \\
band 9 & 0.429 & -0.066 & 0.704 & 0.560 \\
Eigenvalues (\%) & 99.755 & 0.161 & 0.050 & 0.032 \\
\hline Input bands (1589) & & & & \\
\hline band 1 & 0.298 & 0.947 & -0.108 & -0.029 \\
band 5 & 0.594 & -0.124 & 0.670 & -0.425 \\
band 8 & 0.564 & -0.269 & -0.727 & -0.279 \\
band 9 & 0.488 & -0.116 & 0.091 & 0.860 \\
Eigenvalues (\%) & 99.401 & 0.370 & 0.179 & 0.048 \\
\hline Input bands (1689) & & & & \\
\hline band 1 & 0.295 & 0.948 & -0.105 & 0.042 \\
band 6 & 0.607 & -0.132 & 0.674 & 0.398 \\
band 8 & 0.558 & -0.267 & -0.728 & 0.293 \\
band 9 & 0.482 & -0.104 & 0.057 & -0.867 \\
Eigenvalues (\%) & 99.424 & 0.362 & 0.153 & 0.059 \\
\hline Input bands (1348) & & & \\
\hline band 1 & 0.242 & -0.587 & 0.098 & -0.767 \\
band 3 & 0.388 & -0.664 & -0.206 & 0.604 \\
band 4 & 0.642 & 0.402 & -0.626 & -0.185 \\
band 8 & 0.615 & 0.230 & 0.746 & 0.113 \\
Eigenvalues (\%) & 98.657 & 0.824 & 0.386 & 0.132 \\
\hline
\end{tabular}



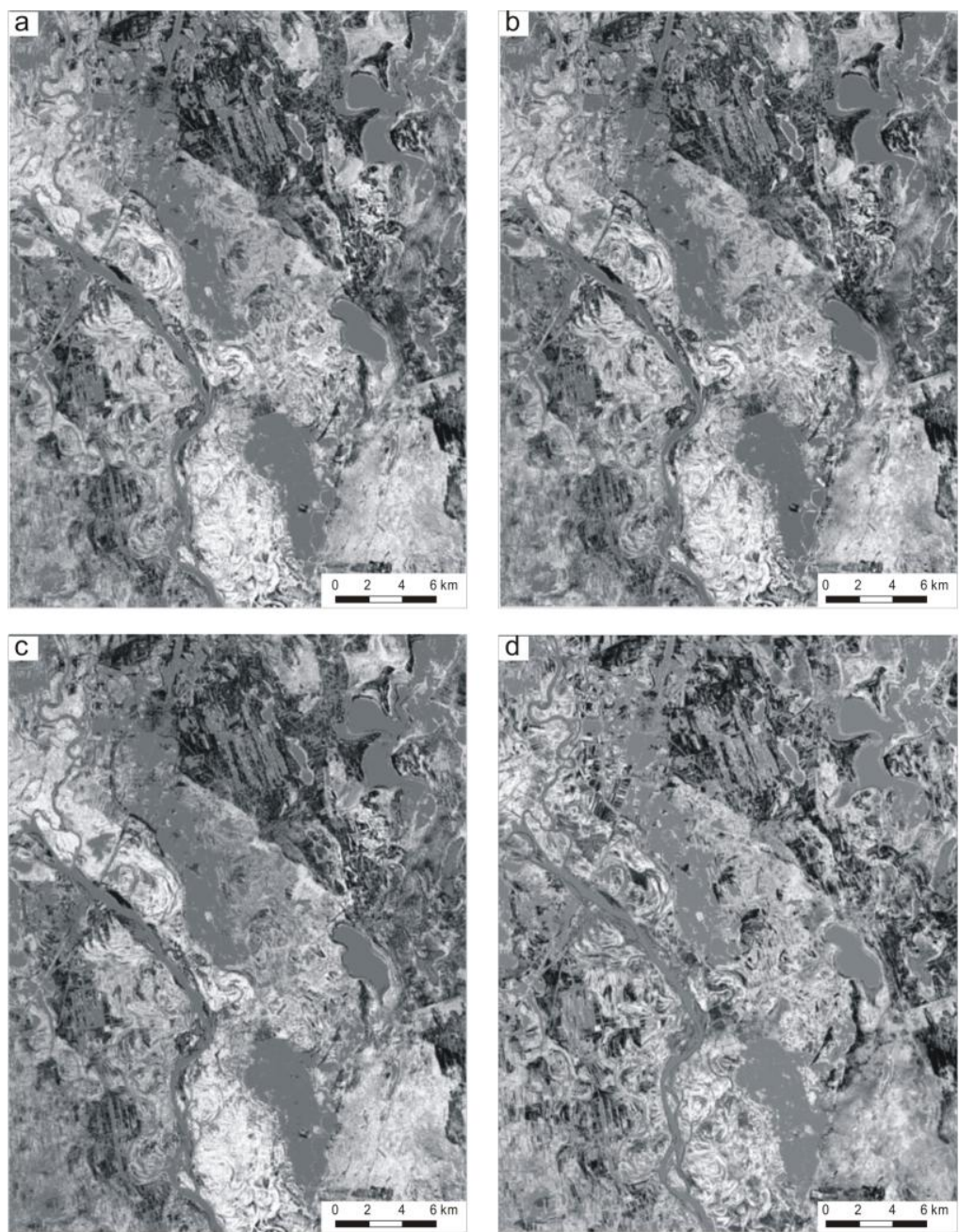

Fig. 2 (a) PC image of 5789-PC2 (the second principal component of the PCA on bands 5689). (b) PC image of 1589-PC3. (c) PC image of 1689-PC3. (d) PC image of 1348-PC3.

Table 3 Size of anomalous areas identified from the four PC images

\begin{tabular}{cccc}
\hline PC image & Size of areas $\left(\mathrm{km}^{2}\right)$ & PC image & Size of areas $\left(\mathrm{km}^{2}\right)$ \\
\hline 5789-PC2 & 11.3 & $1689-\mathrm{PC} 3$ & 21.8 \\
1589-PC3 & 25.0 & $1348-$ PC3 & 20.6 \\
\hline
\end{tabular}

As seen in Fig. 3(a) and 3(b), nearly all the distinguished area (Fig. 3(b)) is covered with Holocene alluvium of floodplain $\left(\mathrm{Qh}^{1 \mathrm{al}}\right.$ and $\left.\mathrm{Qh}^{2 \mathrm{al}}\right)$ and Holocene mantle rock $\left(\mathrm{Qh}^{\text {eol }}\right)$. Moreover, the distribution of the distinguished area is NNW, similar to the direction of strata (Fig. 3(a)). It validates our precious study (Zhang et al., 2011) that hydrocarbon microseepage-induced mineral assemblage is related closely to the surface sediments. Compared with the anomalous area of ETM+ data (Fig. 3(a), Zhang et al., 2011), the distinguished area from ASTER data (Fig. 3(b)) has almost the same distribution, but more widely. It may be due to that the anomalous area of ETM+ data is the overlay area for the 
enrichment of ferrous-iron, the bleaching of red beds, and the clay and carbonate minerals. Moreover, the spatial distribution of light hydrocarbon concentrations of ground soil samples largely agrees with the distribution of hydrocarbon-induced anomalous assemblages.
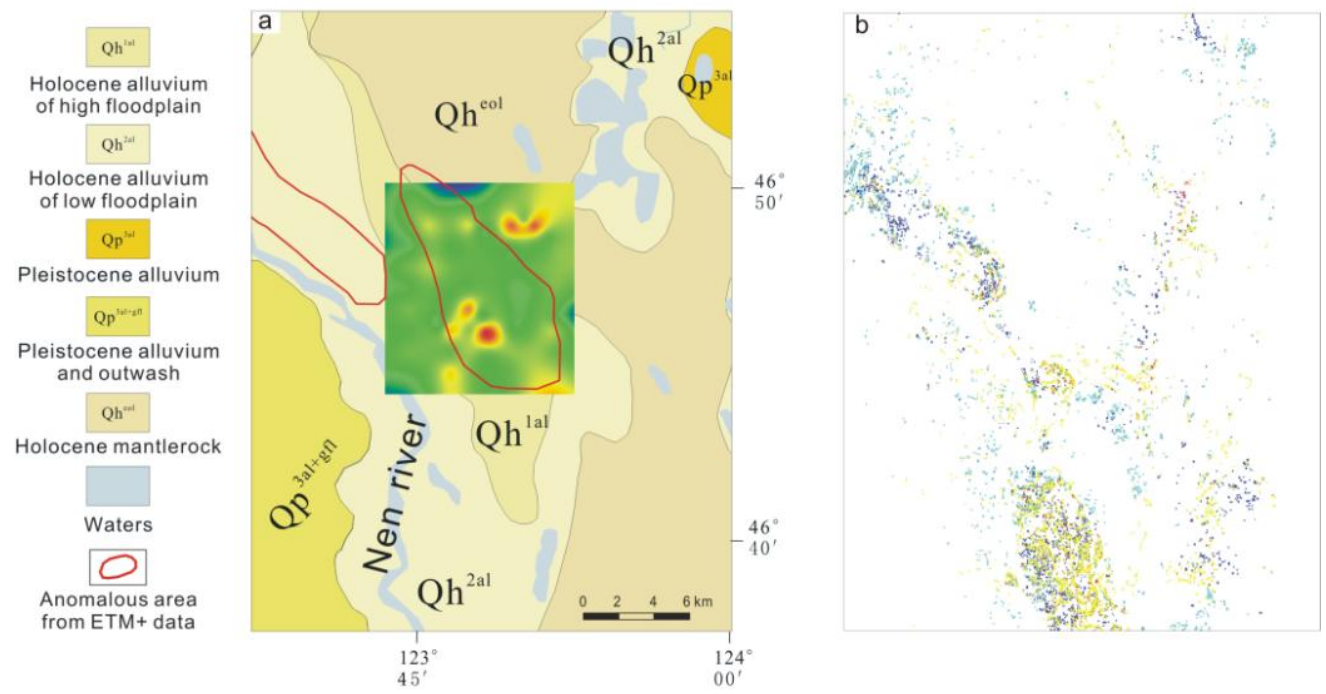

Fig. 3 (a) Surface geological map overlaid by hydrocarbon-induced areas interpreted from ETM+ and contour map of soil acidolysis hydrocarbon values in study area (modified from Zhang et al., 2011). (b) hydrocarboninduced area of clay and carbonate minerals extracted from four PC images respectively.

Finally, it should be pointed out this study just presents the interpretation result of hydrocarbon-induce clay and carbonate minerals. Other anomalous assemblages such as the enrichment of ferrous-iron, the bleaching of red beds should be recognized for further remote sensing exploration.

\section{Conclusion}

5689-PC2 (the second principal component of input bands 5689), 1589-PC3, 1689-PC3 and 1348-PC show outstanding spectral response of hydrocarbon-induced clay and carbonate minerals. According to spectral characteristics of clay and carbonate minerals and the eigenvectors of every PC image, area of clay and carbonate minerals would be manifested as light pixels and density slicing is used to highlight these pixels by the threshold of $X+2 \sigma$. Nearly all the distinguished area is covered with Holocene alluvium of floodplain and Holocene mantle rock and the direction of the distinguished area is similar to the direction of strata. The present study validates our precious study that hydrocarbon microseepageinduced mineral assemblage is related closely to the surface sediments and the spatial distribution of light hydrocarbon concentrations largely agrees with the distribution of hydrocarbon-induced anomalous assemblages.

\section{References}

1. Abrams and Hook, 1995. Simulated ASTER data for geologic studies, IEEE Transactions on Geoscience and Remote Sensing, v. 33, p. 692-699.

2. Abrams M. A., 2005. Significance of hydrocarbon seepage relative to petroleum generation and entrapment: Marine and Petroleum Geology, v. 22, p. 457-477. 
3. Almeida-filho, R., F. P. Miranda, L. S. Galvão and C. C. Freitas, 2002. Terrain characteristics of a tonal anomaly remotely detected in an area of hydrocarbon microseepage, Tucano basin, north-eastern Brazil: International Journal of Remote Sensing, v. 23, p. 3893-3898.

4. Bedell, R.L., 2001. Geological mapping with ASTER satellite: new global satellite data that is a significant leap in remote sensing geologic and alteration mapping. Geological Society of Nevada, Special Publication, v.33, p. 329-334.

5. Clark, R.N., 1999. Spectroscopy of rocks and minerals and principles of spectroscopy. In: Rencz, A.N. (Ed.) , Remote Sensing for the Earth Sciences. John Wiley, New York, p. 3-58.

6. Donovan, T. J., 1974. Petroleum microseepage at Cement, Oklahoma; evidence and mechanism: The American Association of Petroleum Geologists Bulletin, v. 58, p. 429-446.

7. Fujisada, H., 1995. Design and performance of ASTER instrument, in: Breckinridge, J.B. (Ed.), Proceedings of International Society of Optical Engineering, v. 2583, p. $16-25$.

8. Hunt, G.R. and Ashley, R.P., 1979. Spectra of altered rocks in the visible and near infrared. Economic Geology, 74, p. 1613-1629.

9. Kariuki, P. C., T. Woldai and F. Meer, 2004. The Role of Remote Sensing in Mapping Swelling Soils: Asian Journal of Geoinformatics, v. 5, p. 1-11.

10. Matthews, M. D., 1986. Effects of hydrocarbon leakage on Earth surface materials. In Proceedings of the Symposium on Unconventional Methods in Exploration for Petroleum and Natural Gas. Dallas: S. M. U. Press, p. 27-44.

11. Meer, F., P. Dijk, H. Werff, and H. Yang, 2002. Remote sensing and petroleum seepage: a review and case study: Terra Nova, v. 14.

12. Ninomiya, Y., 2003. A stabilized vegetation index and several mineralogic indices defined for ASTER VNIR and SWIR data. Proc. IEEE 2003 International Geoscience and Remote Sensing Symposium (IGARSS'03), v. 3, p. 1552-1554.

13. Rowan L.C., Schmidt R.G. and Mars, J.C., 2006. Distribution of hydrothermally altered rocks in the Reko Diq, Pakistan mineralized area based on spectral analysis of ASTER data. Remote Sensing of Environment, v.104, No. 1, p. 74-87.

14. Ruiz-Armenta, J. R. and Prol-Ledesma, R. M., 1998. Techniques for enhancing the spectral response of hydrothermal alteration minerals in Thematic Mapper Images of Central Mexico: International Journal of Remote Sensing, 1998, v. 19, p. 1981-2000.

15. Sabins, F. F., 1999. Remote sensing for mineral exploration: Ore Geology Reviews, v. 14, p. 157-183.

16. Schumacher, D., 1996. Hydrocarbon-induced alteration of soils and sediments, in D. Schumacher and M. A. Abrams, eds., Hydrocarbon migration and its near surface expression: The American Association of Petroleum Geologists Memoir 66, p. 71-89.

17. Segal, D. B., and I. S. Merin, 1989. Successful use of Landsat Thematic Mapper data for mapping hydrocarbon microseepage-induced mineralogic alteration, Lisbon Valley, Utah: Photogrammetric Engineering and Remote Sensing, v. 4, p. 1137-1145.

18. Tangestani, M. H., and F. Moore, 2000. Iron oxide and hydroxyl enhancement using the Crosta Method: a case study from the Zagros Belt, Fars Province, Iran: International Journal of Applied Earth Observation and Geoinformation, v. 2, p. 140-146.

19. Zhang, G. F., Zheng, Z., Shen, X. H., Zou, L. J., Huang, K. Y., 2011. Remote sensing interpretation of areas with hydrocarbon microseepage in northeast China using Landsat-7/ETM+ data processing techniques. International Journal of Remote Sensing. v.32, p. 6695-6711. 